Journal of the Scholarship of Teaching and Learning, Vol. 21, No. 2, June 2021, pp. 15-42.

doi: 10.14434/josotl.v21i2.27949

\title{
Distance Educators Attitudes and Actions towards Inclusive Teaching Practices
}

\author{
Catherine M. Cash \\ University of Central Florida \\ catherine.cash@ucf.edu \\ Thomas D. Cox \\ University of Central Florida \\ Debbie L. Hahs-Vaughn \\ University of Central Florida
}

\begin{abstract}
As distance education continues to increase, postsecondary institutions must focus on collectively sustaining inclusive instructional techniques that minimize learning barriers and maximize learning opportunities for diverse student populations. This study utilized the Inclusive Teaching Strategies Inventory-Distance Education (ITSI-DE) to analyze faculty $(n=116)$ perspectives and behaviors surrounding online accommodations and inclusive teaching practices based on Universal Design for Learning (UDL) concepts. A Pearson product moment correlation confirmed a statistically significant correlation between faculty attitudes and actions towards inclusive teaching practices. Next, a multivariate analyses of variance (MANOV A) affirmed statistically significant differences between faculty attitudes and actions towards inclusive teaching practices based on gender. The implications of this research and future research recommendations are offered.
\end{abstract}

Keywords: Accessibility and usability, adult learning, attitudes and actions, distance education instruction, inclusive teaching practices, universal design, universal design for instruction, universal design for learning, students with disabilities

As distance education increases as a preferred educational modality, it is crucial for postsecondary educators to examine the extent of accessibility and usability that distance education courses offer to adult learners and student sub-groups (i.e., English Language Learners, students with disabilities...etc). It was estimated by the National Center for Education Statistics (NCES) that between the 2015 to 2016 year 19.4\% of undergraduate students reported having a disability within postsecondary settings (2019). Distance education enrollment is estimated to have increased by $10 \%$ over the last decade with over $90 \%$ of public two-year and four-year institutions offering distance education courses or programs (Reindl, 2013). NCES reported there were 32.2\% of students enrolled in online courses within public postsecondary institutions, $28.7 \%$ enrolled in private non-profit postsecondary institutions, and 71\% enrolled in private for-profit postsecondary institutions for the fall of 2017 (2018). While distance education has increased greater access to postsecondary opportunities, it may also present barriers to accessibility if Universal Design for Learning (UDL) principles are disregarded in the creation of online course content (Burgstahler, Corrigan, \& McCarter, 2004). Therefore, as students with disabilities increase in enrollment within postsecondary settings, it is crucial for educators to apply UDL concepts to distance education courses.

In the 1980s, the Center for Applied Special Technology (CAST) established the concepts of Universal Design for Learning (UDL) based on neuroscience and information technology research, which introduced three instructional principles: a) "multiple means of representation", b) "multiple means of expression", and c) "multiple means of engagement" that could be followed to make distance 
education courses inclusive (Center for Applied Special Technology, 2020). Universal Design for Learning (UDL) was defined by the Higher Education Opportunity Act of 2008 as "A scientifically valid framework for guiding educational practice that - (A) provides flexibility in the ways information is presented, in the ways students respond or demonstrate knowledge and skills, and in the ways students are engaged; and (B) reduces challenges in instruction, provides appropriate accommodations, supports, and challenges, and maintains high achievement expectations for all students, including students with disabilities and students who are limited English proficient" (p. 5) Rose and Meyer (2002) have stated that UDL provides "principles that together form a practical framework for using technology to maximize learning opportunities for every student" (p. 5). Thus, UDL provides a framework of principles to support a broad range of learning styles within distance education courses (Black, Weinberg, \& Brodwin, 2014).

For students with disabilities, distance education courses can present barriers if content is not formatted in an accessible manner (Burgstahler et al., 2004). Within distance education courses, the principles of Universal Design for Learning (UDL) are meant to reduce barriers to accessibility by proactively considering potential impediments to learning (Ann Dell, Dell, \& Blackwell, 2015). Within higher education, the principles of UDL emphasize enhancing inclusiveness and equal access for all students (Ann Dell et al., 2015). Universal Design (UD) views the incidence of a disability not as a shortfall associated with the individual, but more as a social construct, such as gender, race, or ethnicity that should be taken into consideration (Burgstahler \& Cory, 2008). Therefore, universal design aids in decreasing barriers that individuals with disabilities experience when the design of a product or environment is considered to begin with rather than waiting to remove barriers as they occur through individualized accommodations (Seale, 2014). Moreover, UDL principles enhance both accessibility and usability for all students' not just students with disabilities. For instance, incorporating captioning into course videos supports students with hearing impairments as well as students who speak English as a second language. Moreover, students who require noiseless environments may also benefit from captioning. The use of text alternatives for graphic images benefits not only students with disabilities, but also students who may not have access to graphics on their computer due to technical specifications. Therefore, offering students multiple formats within an online course addresses a variety of student learning styles (Burgstahler, Corrigan, \& McCarter, 2004).

\section{Prior Research}

Historically, research on the application of UDL has been conducted at the K-12 level; therefore, postsecondary faculty may not be as well acquainted with the application of UDL concepts (LaRocco \& Wilken, 2013). Additionally, Dallas, Sprong, and Upton (2014) asserted there are a variety of barriers associated with implementing UDL into the curriculum, such as level of familiarity with UDL, time limitations, limited opportunities for training, awareness of disability laws, and student disability knowledge. Additionally, barriers such as a lack of resources and incentives for faculty implementing UDL as well as a lack of institutional support or enforcement of policies surrounding the application of UDL (Dallas et al., 2014). Burgstahler and Cory (2008) asserted that adherence to the attitude "the way we have always done things" may impede faculty or administrators from embracing the value and necessity of applying UDL within postsecondary online courses (p. 280). Other attitudes that may inhibit the implementation of UDL include the attitude that students with disabilities are an inconvenience within courses or the "survival of the fittest attitude" in relation to students (Burgstahler \& Cory, 2008, p. 280).

Cook, Rumrill, and Tankersley (2009) surveyed 307 faculty from eight Midwest postsecondary institutions, and identified significant differences associated with faculty attitudes and actions towards student disability matters. While faculty classified disability related topics as important, their actions

Journal of the Scholarship of Teaching and Learning, Vol. 21, No. 2, June 2021. josotl.indiana.edu 
were contradictory to their attitudes (Cook et al., 2009). For instance, faculty within the study indicated that while attitudes towards policies and disability protocols were strongly valued they were not implemented properly (Cook et al., 2009). Faculty within the study also indicated that they believed that legal issues and Universal Design for Instruction (UDI) where important; however, that these areas were not being overseen adequately (Cook et al., 2009). Moreover, faculty placed little value towards providing students with disabilities accommodations and indicated the implementation of student accommodations was not a focus of the institution (Cook et al., 2009).

Two major standards of Section 508 of the Rehabilitation Act of 1973 apply to higher education institutions (Tandy \& Meacham, 2009). The first standard requires federal divisions or organizations to "ensure, absent an undue burden, that electronic and information technology" may be accessed by federal and public individuals with disabilities who are seeking services from federal divisions or organizations (Edmonds, 2004, p. 53). Initially, this standard only applied to federal divisions or organizations; however, in 1999 Section 508 was interpreted by the U.S. Department of Education to apply to state and public entities, but this interpretation has never been federally adopted (Edmonds, 2004). The second standard includes the Web Content Accessibility Guidelines created by the World Wide Web Consortium (W3C). There are 16 standards in Section 508 that outline the accessibility of electronic and information technology products. Consequentially, no federal law exists to mandate that higher education institutions create accessible distance education courses for students with disabilities. However, while higher education institutions are not legally mandated in the same manner as federal divisions or organizations to apply section 508 Standards to online or distance education courses, many postsecondary institutions are willingly applying such standards in their institutional web accessibility policies to prevent legal consequences associated with negligence (Tandy \& Meacham, 2009). Nevertheless, a standardized method to accommodate students with disabilities within distance education courses does not exist (Bastedo, Sugar, Swenson, \& Vargas, 2013).

The 2013 Managing Online Education Survey found that half of the responding postsecondary institutions lacked formal policies and procedures to mandate distance education programs and courses were upholding compliance with the American with Disabilities Act (ADA). Thirty-six percent out of the 225 colleges and universities that participated in the Managing Online Education Survey stated that ADA compliance was the responsibility of faculty teaching distance education courses; however, twelve percent expressed that it was an institutional responsibility (WICHE Cooperative for Educational Technologies, 2013). Therefore, this indicates that postsecondary institutions may lack consensus on deciding who is responsible for online course accessibility and lack systemic policies to support students with disabilities within online programs and courses.

An action-research project was conducted by LaRocco and Wilken (2013) using a selfdeveloped developed survey with a sample of 46 university faculty and affirmed that faculty reported being concerned about the amount of time, work, and expertise it would take to learn and implement UDL principles. Moreover, the majority of faculty who participated in the study reported entry-level knowledge over UDL principles, which suggested that most were not implementing UDL within their courses (LaRocco \& Wilken, 2013). However, results did indicate that faculty expressed interest towards learning UDL concepts (LaRocco \& Wilken, 2013). Therefore, while faculty may have positive attitudes regarding UDL concepts more training is crucial towards enhancing the competency and skills of faculty to incorporate UDL concepts into their online courses (Dallas et al., 2014). According to Motte (2013), teaching an online course for the first time can be a daunting task for new faculty members due to the unexpected planning and labor commitment it requires to develop an online course. Moreover, teaching online for the first time can cause faculty to experience uncertainty and stress from learning how to utilize new technology (Motte, 2013). As higher education institutions have received pressure to increase online courses faculty have encountered a variety of challenges that include: (1) pressure to create online courses within a short time span, (2) limited access to technology

Journal of the Scholarship of Teaching and Learning, Vol. 21, No. 2, June 2021. josotl.indiana.edu 
support and resources in a timely manner, and (3) deficient training to implement online course instruction (Cole \& Kritzer, 2009).

The Expanding Cultural Awareness of Exceptional Education (EXCEL) survey was developed by Lombardi and Murray (2011), which assessed 289 instructors (full-time) attitudes towards students with disabilities, accommodations, and inclusive teaching practices incorporating UDI. Their findings claimed that female non-tenured faculty from the College of Education with prior training on disability-related topics were more likely to have favorable attitudes towards UD principles and student accommodations (Dallas \& Sprong, 2015; Lombardi \& Murray, 2011). The Inclusive Teaching Strategies Inventory (ITSI) was later formed by Lombardi and Murray by adapting the EXCEL survey, which was used to survey a sample 1,023 faculty within a four-year postsecondary public research university (Lombardi \& Murray, 2011). Their findings indicated differences between faculty attitudes and actions surrounding accommodations and inclusive practices. While faculty reported positive attitudes towards inclusive instructional practices, their actions were not consistent (Lombardi, Murray, \& Gerdes, 2011). Multiple regression analysis findings indicated that faculty tended to have stronger favorable attitudes towards accommodations and inclusiveness if they had completed prior disability-related training (Dallas \& Sprong, 2015).

Lombardi, Murray, and Dallas (2013) also assessed attitudes towards student disability topics and inclusive instructional practices using the ITSI with 612 faculty working within two medium public four-year Midwestern universities, and the findings were consistent with prior research. They asserted that the extent of disability-related training and experience faculty possessed influenced attitudinal and action responses on the ITSI instrument (Lombardi et al., 2013). West, Novak, and Mueller (2016) administered the ITSI to 222 College of Education instructors employed by a four-year postsecondary institution in the Pacific Northwest, and also confirmed that instructors who possessed a strong understanding of disability laws as well as well as knowledge to implement policies possessed greater self-efficacy to initiate accommodations for students with disabilities. Dallas, Sprong, and Kluesner (2016) examined if there was a correlation between faculty who obtained prior disability training, and their attitudes and actions towards inclusive teaching practices. The study was conducted within three four-year public universities, and the findings suggested that faculty with prior training possessed higher positive attitudes towards inclusive teaching practices, and were more likely to implement inclusive teaching practices within their courses (Dallas et al., 2016). Therefore, providing faculty with disability-related training may enhance their capability to implement accommodations and enhance inclusiveness (West et al., 2016).

Additionally, international research comparing faculty attitudes and actions regarding inclusive instruction from one medium Pacific Northwest university in the United States $(n=231)$, one comprehensive university in Canada $(n=315)$, and seventy-six public and private universities across Spain $(n=649)$ found significant differences between attitudes and actions across the ITSI instrument subscales (Lombardi, Vukovic, \& Sala-Bars, 2015). Therefore, international research findings have also affirmed the prior research findings that while faculty scored highly in their attitudes towards inclusive instruction their actions were not consistent with their attitudes (Lombardi et. al., 2015). However, Hartsoe and Barclay (2017) administered the ITSI to a sample of 653 faculty teaching within a medium sized public university in the mid-south and identified correlations between faculty knowledge, beliefs, and confidence levels. This may indicate that faculty awareness levels towards supporting the needs of diverse learners may be increasing as well as willingness to consider implementing inclusive pedagogies (Hartsoe \& Barclay, 2017).

To achieve optimal success in promoting the implementation of UDL by faculty, it is crucial that postsecondary institutions integrate a variety of learning approaches within professional development and training experiences (LaRocco \& Wilken, 2013). Effective faculty professional development programs should be grounded in adult-learning theory, and provide a direct connection

Journal of the Scholarship of Teaching and Learning, Vol. 21, No. 2, June 2021. josotl.indiana.edu 
between instructors past teaching experience and professional learning (LaRocco \& Wilken, 2013). Consequently, most instructors learn to teach using the lecture method, which is a pedagogical approach whereby students are passive in the learning process; however, within distance education environments, instructors could benefit from learning theoretical models like andragogy (Cercone, 2008). Cox (2013) affirmed that pedagogy was a method where the instructor is in charge of the learning content, means of delivery, and style of assessment. In contrast, andragogy espouses, that adult learners are motivated to learn based on how the level of knowledge gained will assist them towards performing tasks or problem solving within their lives (King \& Cox, 2011). Therefore, effective professional development programs should actively engage participants in meaningful learning experiences that draw on prior experiences and allow opportunities for reflection (LaRocco \& Wilken, 2013).

\section{Theoretical Framework}

Rogers' diffusion of Innovations theory offers a theoretical basis for conceptualizing the attitudes and actions that faculty experience when making the decision to adopt or reject technology innovations within postsecondary settings (Parisot, 1995; Medlin, 2001; Sahin, 2006). Rogers' theory provides a theoretical explanation of individual's decision-making process within organizational systems. Rogers asserted that an innovation was "anything perceived as new by an individual or group," and claimed that diffusion occurred through a "process by which an innovation is communicated among members of a social system” (McLean, 2005, p. 3). Rogers' theory highlighted that there were five categories to describe individual's affinity towards innovativeness: (1) "innovators", (2) "early adopters", (3) "early majority", (4) "late majority", and (5) "laggards" (McLean, 2005, p. 3). Individuals who were "innovators" were more likely to take risks and spend greater amounts of time towards learning and adapting innovations, and individuals deemed "early adopters" were more likely to see the potential benefits associated with technology innovations (McLean, 2005, p. 3). In contrast, individuals identified as the "early majority" were more skeptical, practical, and calculated in their approach so they tended to observe others utilizing an innovation first before adopting it into their own practice (McLean, 2005, p. 3). Lastly, individuals who fell into the category of the "late majority" or "laggards" were even more skeptical and resistant to change and often did so under pressure or imposed duty (McLean, 2005, p. 3).

Rogers' diffusion of innovations theory contends faculty are likely to move slowly through the adoption of technology innovations because individuals fall along a continuum of innovation adoption with an estimated $2.5 \%$ of individuals classified as "innovators," $13.5 \%$ classified as "early adopters," $34 \%$ classified as "early majority," 34\% classified as "late majority," and 16\% classified as "laggards" (Rogers, 2003, p. 281). Therefore, based on Rogers' diffusion of innovations theory the assumption is that between $2.5 \%$ to $13.5 \%$ of faculty may embrace innovations early on; whereas, $34 \%$ of faculty embrace an innovation only after a period of time, another $34 \%$ will embrace an innovation with great hesitation, and 16\% will prefer familiar methods against embracing innovations (Baltaci-Goktalay, 2006).

According to Samarawickrema and Stacey (2007), Rogers' diffusion of innovations theory elucidates motivations surrounding an individual's adoption of innovations, which are novel forms of knowledge, methods, or innovative entities that an individual encounters. Rogers' diffusion of innovation theory purposes that individuals precede through five evaluation stages in the "decision making process": (1) "knowledge", (2) "persuasion", (3) “decision", (4) “implementation", and (5) "confirmation" (Rogers, 2003, p. 169). Theoretically, individuals will initially seek out information and weigh the advantages and disadvantages associated with the innovation before deciding whether to adopt or reject an innovation (Sahin, 2006). Therefore, Rogers stated the "innovation-decision process

Journal of the Scholarship of Teaching and Learning, Vol. 21, No. 2, June 2021. josotl.indiana.edu 
is essentially an information-seeking and information processing activity" that individuals are driven to proceed through to reduce uncertainty associated with adopting an innovation (Rogers, 2003, p. 172).

Creating a climate of change within postsecondary institutions requires buy in from educators at the micro-level of an organization. To spread awareness and increase the adoption of an innovation, such as the application of UDL concepts within technology, faculty must first possess knowledge, understanding, and expertise in implementing UDL technology concepts. However, according to a study performed by the UCLA Higher Education Research Institute faculty members were hesitant to incorporate new technologies because it caused a great deal of stress (Baltaci-Goktalay, 2006). Therefore, the manner that faculty view and understand UDL concepts and technologies may greatly influence their decisions and actions. Baltaci-Goktalay (2006) insisted the "diffusion of innovations as a process by which an innovation is communicated through certain channels over time among the members of a social system" (p. 1). According to Baltaci-Goktalay both a "top-down" and "bottom-up" approach would be most effective for the communication and adoption of new innovations within an institution (Baltaci-Goktalay, 2006).

Huang, Deggs, Jabor, and Machtmes (2011) claimed that faculty awareness of a technology innovations was the strongest predictor that influenced their decision to adopt a technology innovation; moreover, "perception of ease" as well as support from administration were also strongly positively linked to influencing their decisions to adopt technology innovations (p. 7). In contrast, Samarawickrema and Stacey found that faculty adoption of technology innovations was less influenced by their ability to utilize the technology and more influenced by their technology preferences, motivation to use technology, attitude concerning changes, and methods of learning. Moreover, administrative, economic, and political forces exerted a great deal of influence over faculty decisions to adopt technology innovations (Samarawickrema and Stacey, 2007). Porter and Graham (2016) conducted a study on the adoption of blended learning (BL) methods, which identified the top three reasons for faculty adopting BL methods were receiving satisfactory organizational support, technical assistance, and sufficient aid towards pedagogical methods.

Conversely, a significant number of barriers may impede the adoption of innovations, such as new distance education methods or concepts. Concerns over student relationships and the quality that distance education methods provide as well as concerns that faculty positions will diminish may cause faculty hesitation towards adopting distance education methods (Bacow, Bowen, Guthrie, Lack, \& Long, 2012). Moreover, the amount of time, additional effort, lack of technical assistance, and concerns over intellectual property may negatively affect faculty decisions to adopt distance education methods (Bacow et al., 2012). In a study conducted by Weston (2005) it was asserted that faculty were less likely to incorporate technology if they felt unskilled in applying the technology to their course content. Surry, Stefurack, and Gray (2011) reported that faculty expressed feeling they lacked the time and administrative support to obtain training to incorporate new technologies into their courses. Moreover, Polly, Mims, Inan and Sheperd (2010) affirmed that faculty reported experiencing difficulty incorporating new technologies learned from professional development trainings into their courses without some kind of follow up or mentoring support. Therefore, micro and macro organizational and administrative factors may influence faculty decisions to adopt or reject the application of technology innovations, such as the application of UDL concepts into their distance education courses.

Journal of the Scholarship of Teaching and Learning, Vol. 21, No. 2, June 2021. josotl.indiana.edu 


\section{Purpose}

This study investigated whether a correlation existed between faculty attitudes and actions concerning accommodations and inclusive teaching practices based on UDL within fully online courses. There is a need to examine if correlations exist between faculty attitudes and actions associated with accessibility and UDL principles within distance education environments. Prior research examining postsecondary faculty teaching face-to-face courses affirmed significant differences between faculty attitudes and actions towards inclusive teaching practices. Prior findings acknowledged that faculty positively approved of UD principles; however, they were not actively applying UD principles to their postsecondary lecture style courses (Lombardi \& Murray, 2011). Hartsoe and Barclay (2017) recommended that future research should modify the Inclusive Teaching Strategies Inventory (ITSI) to capture a larger number of UD concepts and participant responses surrounding inclusive teaching practices. Prior research has also found variance associated with demographic factors, such as gender, college affiliation, age, and instructional rank (Gawronski, Kuk, \& Lombardi., 2016; Hartsoe \& Barclay, 2017; Lombardi \& Murray, 2011); therefore, this study focused on examining those areas further.

\section{Research Questions}

This study answered the following research questions:

- RQ1: Is there a correlation between faculty attitudes and actions concerning online academic accommodations and inclusive teaching practices?

- RQ2: What are the differences in attitudes and actions concerning online academic accommodations and inclusive teaching practices based on faculty on faculty age, gender, instructional rank, and college affiliation?

\section{Method}

\section{Population}

A census was conducted with a population of full-time faculty $(\mathrm{N}=878)$ from a large four-year postsecondary metropolitan research university within the south-east. Faculty members who had completed a mandatory online instructional course through the Center for Distributed Learning (CDL) were invited to participate in the study. Prior to designing, developing, and teaching online courses, all full-time faculty members were required by the institution to complete a mandatory online course. The study delimited the population to include only full-time faculty (i.e., professor, associate professor, assistant professor, instructor, or lecturer) who contained experience teaching and designing one or more fully online courses.

Sample

A 22\% response rate was achieved with 194 respondents. Two missing values were identified for 1 respondent who did not disclose, "age" and "gender" (independent variables), these cases were excluded due to the small proportion they represented in the overall sample size. There were 57 respondents screened out for not meeting the study participation criteria, and 9 respondents were removed due to survey incompletion that ranged from $22 \%$ to $100 \%$. Additionally, 7 respondents (i.e., 
2 adjuncts, 4 faculty administrators, 1 visiting faculty) were removed to conserve the study criteria to include only full-time faculty. Four outliers were removed to establish univariate and multivariate normality assumptions; therefore, the analytic sample size consisted of 116 respondents.

\section{Instrument}

To answer the research questions presented in this study the Inclusive Teaching Strategies Inventory (ITSI) was adapted to create a new instrument, the Inclusive Teaching Strategies Inventory-Distance Education (ITSI-DE) to measure faculty attitudes and actions associated with academic accommodations and inclusive instruction within distance education courses (Lombardi et al., 2015). The ITSI is a self-report measure that was previously known as the Expanding Cultural Awareness of Exceptional Learners (EXCEL) survey (Lombardi et al., 2011). Dallas and Sprong (2015) have claimed that the ITSI is the "only survey known to incorporate principles from the three major educational UD models (e.g., UDI, UDL, UID)” (p.20).

To ensure the adapted ITSI-DE was conveying clarity and the intended meaning content validity was established in a variety of ways. First, expert reviews were obtained from individuals who were specialists the field of focus working within the university Center for Distributed Learning (CDL) and Student Accessibility Services (SAS) departments. Obtaining expert reviews from individuals who are specialists in the field of focus for the study provided increased content validity (Passmore, Dobbie, Parchman, \& Tysinger, 2002). Next, cognitive interviews were conducted using the adapted ITSI-DE with a small group of faculty who were part of the institutions Accessibility Services Faculty Committee, and represented different colleges within the university. Faculty members participating in the cognitive interviews were excluded from the population of faculty utilized for the study. The creator of the ITSI instrument, Dr. Lombardi, was also contacted to review the adjustments made to the instrument. Additionally, Exploratory Factor Analysis (EFA) was performed on the results of the study, to provide evidence of construct validity between the original and adapted instrument scores.

Based on the modifications that were made within the phases of review, the adapted ITSI-DE contained a total of 28 items measuring actions (i.e., Accommodations, Accessible Course Materials, Inclusive Lecture Strategies, Inclusive Classroom, Inclusive Assessment) and 34 items measuring attitudes (i.e., Accommodations, Accessible Course Materials, Inclusive Lecture Strategies, Inclusive Classroom, Inclusive Assessment, Disability Law \& Concepts).

\section{Data Analysis}

\section{Validity}

The literature on the ITSI has acknowledged that the instrument has undergone extensive exploratory and confirmatory factor analysis (Lombardi et al., 2011, 2015; Lombardi \& Murray, 2011). The ITSI instrument possesses evidence of content, convergent, and discriminant validity (Gawronski et al., 2016; Lombardi \& Murray, 2011). Additionally, a cross-validation study using exploratory and confirmatory factor analysis suggested a seven-factor organization for the ITSI (Gawronski et al., 2016; Lombardi et al., 2015). As a part of this research study, two exploratory factor analyses (EFA) were conducted to provide further construct validity evidence to the ITSI-DE, which was adapted from the original ITSI instrument. The two exploratory factor analysis provided evidence of internal validity supporting that there is evidence that the scores obtained from the ITSI-DE provide a valid assessment of actions and attitudes.

Journal of the Scholarship of Teaching and Learning, Vol. 21, No. 2, June 2021. josotl.indiana.edu 
First, an EFA was conducted on 28 action response items, which were scaled from zero to four $(0=$ no opportunity, $1=$ never, $2=$ sometimes, $3=$ most of the time, $4=$ always). Initial factorability was distinguished through an analysis of the following methods: (a) bivariate correlations, (b) Kaiser-Meyer-Olkin measure of sampling adequacy (overall and individual), (c) Barlett's test of sphericity, (d) communalities, and (e) anti-image matrix. To extract the factors, maximum likelihood estimation with pro-max rotation was utilized, and the Kaiser-Guttman rule (eigenvalues $>1$ ) was applied. A six-factor model was suggested by the factor loadings, and a review of the scree plot also suggested that after the six factors eigenvalues began to flatten out, which may support a six-factor solution. In contrast, parallel analysis of 100 and 1000 parallel data sets using permutated data suggested a five-factor model was appropriate (i.e., the first five raw data eigenvalues were greater than the random and permutated mean and $95^{\text {th }}$ percentile eigenvalues; all other raw data was less in value). A final decision to support the retention of a five-factor solution was based on the findings of the parallel analysis based on the level of accuracy this analysis provides (see Table 1 of Factor Loadings and Communalities, for more detail).

While the initial factor loadings and Cattell's scree test indicated a six-factor model, the scree test has been known to suffer from subjective interpretation, poor interrater reliability, over-or-under factoring, and ambiguity (Cattell, 1978; Hahs-Vaughn, 2017; Knight, 2000; Norris \& Lecavalier, 2009). In contrast, parallel analysis has been asserted as one of the most accurate methods of determining the number of factors to retain (Hahs-Vaughn, 2017, Knight, 2000, Mumford, Ferron, Hines, Hogarty, \& Kromrey, 2003). About $52.4 \%$ of the total variance explained was represented within the five-factor solution when extracted. Overall, the twenty-three items contributed to a complex factor structure, and had a primary factor loading at or above the recommended .30 value. All variables had strong factor loadings for the five factors in the factor structure (see Table 2 of Factor Correlation Matrix, for more detail).

Second, an EFA was conducted on 34 attitudes response items, which were scaled from one to six $(1=$ strongly disagree, $2=$ disagree, $3=$ somewhat disagree, $4=$ somewhat agree, $5=$ agree, 6 $=$ strongly agree). Initial factorability was determined through an analysis of the following methods: (a) bivariate correlations, (b) Kaiser-Meyer-Olkin measure of sampling adequacy (overall and individual), (c) Bartlett's test of sphericity, (d) communalities, and (e) anti-image matrix. To extract the factors, the maximum likelihood estimation with promax rotation was utilized and the KaiserGuttman rule (eigenvalues $>1$ ) was applied. A nine-factor model was suggested by the factor loadings, and a review of the scree plot also suggested that after nine-factors eigenvalues began to flatten out, which may support a nine-factor solution.

In contrast, a parallel analysis of 100 parallel data sets using permutated data suggested a sevenfactor model was appropriate (i.e., the first seven raw data eigenvalues were greater than the random and permutated mean and $95^{\text {th }}$ percentile eigenvalues; all other raw data was less in value). Additionally, an analysis of 1000 parallel data sets using permutated data was performed, and suggested a six-factor model may be appropriate (i.e., the first six raw data eigenvalues were greater than the random and permutated mean and 95th percentile eigenvalues; all other raw data was less in value). Within the literature Cokluk and Kocak (2015), cited that Horn (1965) had asserted no "strict rules" on the number of iterated data sets to use in the calculation of the mean eigenvalues (p. 541). While some researchers have proposed using 500 to 1000 (Hayton, Allen \& Scarpello, 2004), prior research studies have also shown no significant differences in using 1 to 100 data iterations (Crawford \& Koopman, 1979). Therefore, based on the results of the parallel analysis using 100 parallel data sets, and an examination of the factor loadings a seven-factor model was suggested. The seventh factor, Inclusive Assessment, had two very strong factor loadings at .948 (item Q27) and .923 (item Q28) as well as an acceptable factor loading at .38 (item Q26); therefore, the decision was made to retain the seventh factor using 100 parallel data sets( see Table 3 of Factor Loadings and Communalities, for more detail). About $57.8 \%$ of the total variance explained was represented within the seven-factor solution when extract. Overall, the thirty-four items contributed to a complex factor structure and contained a

Journal of the Scholarship of Teaching and Learning, Vol. 21, No. 2, June 2021. josotl.indiana.edu 
primary factor loading at or above the recommended .30 value. All variables had strong factor loadings for the seven factors in the factor structure (see Table 4 of Factor Correlation Matrix, for more detail).

\section{Reliability}

To evaluate whether the items of the ITSE-DE possessed acceptable reliability levels, Cronbach's alpha was calculated for the overall score, scale scores (attitudes and actions) and the seven subscale scores. Cronbach's alpha provides a method to test the internal consistency of the scores that have been gathered from respondents. A Cronbach's alpha score of 70 has been affirmed as an acceptable level (Heale \& Twycross, 2015). Overall, a Cronbach's alpha score of .93 was calculated for the internal consistency of the ITSE-DE instrument ( $\mathrm{N}=57$ items), which is considered excellent. A Cronbach's alpha score of .86 (6 subscales, $\mathrm{n}=23$ items) was calculated for the action scale scores, and .90 (7 subscales, $\mathrm{n}=34$ items) for the attitude scale scores, which suggested strong and excellent levels of internal consistency. 
Table 1: Factor Loadings and Communalities Action Response Items.

Items

12

Factors

Communality

F1: Inclusive Classroom and Course Materials

Q24. I do use interactive technology to facilitate class communication and participation (e.g., Discussion Board)

Q25. I do create multiple opportunities for engagement

$.827 \quad .393$

34

4

5

Q21. I do use a variety of online instructional formats, such as

small group projects, video lectures and discussion board activities

.476

.272

.496

.615

.625

Q6. * I do apply heading styles (e.g., Heading 1, Heading 2, .306

Heading 3) to ALL document titles and subsections (e.g., Word, HTML, PDF, etc.) to organize text content in a document

Q13. * I do structure online communication (e.g., discussion $\mathbf{. 6 7 6}$ board threads, course chat threads)

\section{F2: Inclusive Classroom}

Q17. I do present course information in multiple formats (e.g., .414 short videos, text, graphics, audio, video, podcast)

Q22. I do supplement modules and reading assignments with 486

visual aids (e.g., photographs, videos, diagrams, interactive simulations)

Q23. I do use technology so that my course material can be .553 available in a variety of formats (e.g., podcast of lecture available for download, course readings available as $\mathrm{mp} 3$ files)

\section{F3: Accommodations}

Q1. * I do provide video screen capture or transcripts of captioned videos to students with documented disabilities

Q2. I do make individual accommodations for students who have disclosed their disability to me

Q3. I do arrange extended time on exams for students who have documented disabilities

Q4. I do extend the due dates of assignments to accommodate the needs of students with documented disabilities

$.267 \quad .273 \quad .165$

$\begin{array}{llll}.314 & .316 & .446 & .470\end{array}$

.822

$.352 \quad .448$

.707

.968

F3: Course Modifications 


\section{Items}

Q10. I do allow ANY student to complete extra credit assignments in my course(s)

F3: Accessible Course Materials

Q8. * I do post only video clips that have been captioned

.409

.284

665

Q7. * I do post electronic versions of course handouts containing

.320

.266 .

.441 alternative text (alt text) on all images

F4: Inclusive Lecture Strategies

Q15. I do summarize key points throughout each online class module

Q16. I do connect key points with larger course objectives within $\quad .296$

.904

online class modules

Q14. I do post an outline/agenda of the topics that will be covered in each online class module

Q20. I do post a statement online in different locations inviting

ALL students to discuss their needs with me

Q18. I do review my online course materials in advance to $.385 \quad .35$

.753

.587

anticipate any instructional barriers

F5: Inclusive Assessment

Q27. I do allow students to express comprehension in multiple $\quad .592$

ways

Q26. I do allow students to demonstrate the knowledge and skills

in ways other than traditional tests and exams (e.g., written essays, portfolios, journals)

Q28. I do be flexible with assignment deadlines in my course(s) $\quad \mathbf{3 2 5}$

$.435 \quad .296 \quad .234$

for ANY student who expresses a need

Note. Bold values indicate the items that loaded to each factor. Coefficients $<0.30$ have been removed from the table to ease interpretation.

An asterisk has been placed next to newly added items. 
Table 2: Factor Correlation Matrix.

\begin{tabular}{lllll} 
Factor & $\mathbf{1}$ & $\mathbf{2}$ & $\mathbf{3}$ & $\mathbf{4}$ \\
\hline 1. Inclusive Classroom and Course Materials & 1.000 & & & \\
\hline 2. Inclusive Classroom & .519 & 1.000 & & \\
\hline 3. Accommodations, Modifications, and Course Materials & .015 & .138 & 1.000 & \\
& & & & \\
\hline 4. Inclusive Lecture Strategies & .359 & .355 & .082 & 1.000 \\
\hline 5. Inclusive Assessment & .595 & .395 & -.063 & .341 \\
\hline
\end{tabular}

Table 3: Factor Loadings and Communalities Attitudes Response Items. Items

\begin{tabular}{lll} 
& Factors \\
\hline 1 & 2 & 3
\end{tabular}

3

F1: Inclusive Classroom

Q22. I believe it is important to supplement modules and reading assignments with visual aids (e.g., photographs, videos, diagrams, interactive simulations).

Q21. I believe it is important to use a variety of online instructional formats, such as small group projects, video lectures and discussion board activities.

Q17. I believe it is important to present course information in multiple formats (e.g., short videos, text, graphics, audio, video, podcast).

Q23. I believe it is important to use technology so that my course material can be available in a variety of formats (e.g., podcast of lecture available for download, course readings available as mp3 files).

.845

$4 \quad 5$

5

6

Communality

.431

.332


Q24. I believe it is important to use interactive technology to facilitate class communication and participation (e.g., Discussion Board).

Q18. I believe it is important to review my online course materials in advance to anticipate any instructional barriers.

Q25. I believe it is important to create multiple opportunities for engagement.

Q20. I believe it is important to post a statement online in different locations inviting ALL students to discuss their needs with me.

Q19. I believe it is important to include a statement in my syllabus inviting students with disabilities to discuss their needs with

\begin{tabular}{lll} 
& & Fact \\
1 & 2 & 3 \\
\hline
\end{tabular}

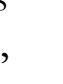

.64

me.

\section{F2: Disability Law \& Concepts}

Q30. I am confident in my understanding of the Americans with Disabilities Act (1990).

Q29. I am confident in my understanding of the legal definition of disability.

Q31. I am confident in my understanding of section 504 of the Rehabilitation Act of 1973.

Q32. I am confident in my responsibilities $\quad 318$ as an instructor to provide or facilitate disability related accommodations.

Q34. I am confident in my understanding .374 of Universal Design for Learning.

.648

.647

.551

.287

.637

.394

5

.955

.564

.397

.778

.291

.582

.276

.533

.652

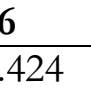

.496

.296

.500

.440

.895

.384

.776

.358

.261

.355

.670

.597

.381

.767

.537

.503

.362

.436

.672 
Q33. I am confident in my knowledge to

$\begin{array}{llll}1 & 2 & 3 & 4\end{array}$

$4 \quad 5$

6

make adequate accommodations for

students with disabilities in my course(s).

F3: Accommodations

Q3. I believe it is important to arrange

extended time on exams for students who have documented disabilities.

Q2. I believe it is important to make individual accommodations for students who have disclosed their disability to me.

Q1. * I believe it is important to provide video screen capture or transcripts of

captioned videos to students with documented disabilities.

Q4. I believe it is important to extend the due dates of assignments to accommodate the needs of students with documented disabilities.

F4: Accessible Course Materials

Q6. * I believe it is important to apply

heading styles (e.g., Heading 1, Heading 2, Heading 3) to ALL document titles and subsections (e.g., Word, HTML, PDF, etc.) to organize text content in a document.

Q7. * I believe it is important to post images.

Q8. * I believe it is important to post only $\quad .367$

video clips that have been captioned. 
Q5. * I believe it is important to use a font
and color scheme on course website (e.g.,

$\begin{array}{lll}1 & 2 & 3\end{array}$

4

5

56

6

7

and color scheme on course website (e.
Canvas) that is readable for all students.

\section{F5: Course Modifications}

Q11. I believe it is important to reduce the

course reading load for ANY student who expresses a need.

Q12. I believe it is important to reduce the overall course reading load for a student with a documented disability even when I would not allow a reduced reading load for another student.

Q9. I believe it is important to allow a

student with a documented disability to

complete extra credit assignments.

Q10. I believe it is important to allow ANY

student to complete extra credit assignments in my course(s).

\section{F6: Inclusive Lecture Strategies}

Q15. I believe it is important to summarize key points throughout each online class module.

Q16. I believe it is important to connect key points with larger course objectives within online class modules.

Q14. I believe it is important to post an outline/agenda of the topics that will be covered in each online class module.

Q13. * I believe it is important to structure online communication (e.g., discussion board threads, course chat threads)

\begin{tabular}{|c|c|c|c|c|c|}
\hline .444 & .344 & .469 & .839 & & 249 \\
\hline .499. & .366 & .517 & .748 & & .836. \\
\hline & .345 & .287 & .728 & .272 & .938 \\
\hline .679 & .280 & .321 & .416 & & .643 \\
\hline
\end{tabular}




\section{Items}

\begin{tabular}{lll} 
& & Factors \\
\hline 1 & 2 & 3
\end{tabular}

4

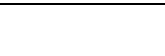

5

6

7

F7: Inclusive Assessment

Q27. I believe it is important to allow .528 students to express comprehension in multiple ways.

Q26. I believe it is important to allow .465 students to demonstrate the knowledge and skills in ways other than traditional tests and exams (e.g., written essays, portfolios, journals).

Q28. I believe it is important to be flexible with assignment deadlines in my course(s)

.401

87

$\begin{array}{llllll}.324 & .394 & .923 & .592\end{array}$

for ANY student who expresses a need.

Note. Bold values indicate the items that loaded to each factor, and communalities greater than 0.30 . Coefficients $<0.30$ have been removed from the table to ease interpretation. An asterisk has been placed next to newly added items.

\section{Table 4. Factor Correlation Matrix.}

\begin{tabular}{|c|c|c|c|c|c|c|c|}
\hline Factor & 1 & 2 & 3 & 4 & 5 & 6 & 7 \\
\hline 1. Inclusive Classroom & 1 & & & & & & \\
\hline 2. Disability Law and Concepts & .275 & 1 & & & & & \\
\hline 3. Accommodations & .158 & .006 & 1 & & & & \\
\hline 4. Accessible Course Materials & .622 & .448 & .176 & 1 & & & \\
\hline 5. Course Modifications & .277 & .175 & .032 & .281 & 1 & & \\
\hline 6. Inclusive Lecture Strategies & .445 & .422 & .211 & .485 & .292 & 1 & \\
\hline 7. Inclusive Assessment & .523 & .084 & .040 & .412 & .344 & .405 & 1 \\
\hline
\end{tabular}


In analyzing the subscale scores, Cronbach's alpha values ranged from .75 to .92, which suggested acceptable levels of internal consistency comparable to the ITSI. The following alpha values were reported for each subscale: (a) Accommodations $=.75(n=8$ items), (b) Accessible Course Materials $=.80(n=7$ items), (c) Course Modifications $=.79(n=5$ items), (d) Inclusive Lecture Strategies $=.85(n=8$ items $)$, (e) Inclusive Classroom $=.92(n=17$ items $)$, ( $\mathrm{f})$ Inclusive Assessment $=.84(n=6$ items $)$, and $(\mathrm{g})$ Disability Law and Concepts $=.86(n=6$ items). The internal consistency calculated for the ITSE-DE was consistent with prior values reported for the ITSE, which ranged from .70 to .85 (Lombardi et al., 2013).

$R Q$ 1: Is there a correlation between faculty attitudes and actions concerning online academic accommodations and inclusive teaching practices?

First, a Pearson correlation coefficient was performed using the data that was collected from the ITSIDE and screened for normality $(N=116)$, to examine if a correlation existed between faculty attitudes and actions inclusive instructional practices. Assumptions of linearity and homogeneity of variancecovariance were met. The Pearson correlation coefficient was .737, which is considered a moderately strong positive correlation indicating a relationship between faculty attitudes and actions. The coefficient of determination was .54 signifying that the shared variance between attitudes and actions was $54 \%$. According to Cohen (1988), a moderately strong relationship was identified between faculty attitudes and actions, $r=.737, r^{2}=.054, N=116, p=.000$. The correlation coefficient was statistically significant; therefore, the null hypothesis was rejected, and there was sufficient evidence to support a significant relationship between faculty attitudes and actions concerning inclusive instructional practices. As faculty, attitudes towards inclusive teaching practices increased their actions towards inclusive teaching practices also increased.

RQ 2: What are the differences in attitudes and actions concerning online academic accommodations and inclusive teaching practices based on faculty on faculty age, gender, instructional rank, and college affiliation?

Second, using the data that was collected from the ITSI-DE and screened for normality $(N=116)$, a $2 \times 4$ multivariate analysis of variance (MANOVA) was conducted to determine if there were significant mean differences between attitudes and actions concerning online inclusive teaching strategies based on four predictor variables (i.e., faculty age, gender, instructional rank, college affiliation). Assumptions of univariate and multivariate normality, independence, linearity, noncollinearity, and homogeneity of variance were met. Females mean scores were highest (actions $\bar{x}=2.91, S D=.49$; attitudes $\bar{x}=4.91, S D=.54$ ) in comparison to males mean scores (actions $\bar{x}=2.53, S D=.53$; attitudes $\overline{\mathrm{x}}=4.48, \mathrm{SD}=.61)$. Wilks Lambda was statistically significant for the main effect of gender, which suggests that the combined dependent variables differed, on average between males and females, $\Lambda=$ $.898, F(2,84)=4.787, p<.011$, partial $\eta^{2}=.102$. Partial eta squared suggested a moderate main effect for gender (males and females).

Therefore, discriminant analysis was performed to identify whether gender (male vs. female) differences could be anticipated from two continuous variables (attitudes and actions). The overall Wilk's lambda was statistically significant, $\Lambda=.866, \chi^{2}=16.301, p=.000$, partial $\eta^{2}=.04$ indicating that the predictors did differentiate between gender (males vs. females). The canonical $R^{2}$ was .13 , indicating that $13 \%$ of the variance of the scores for the discriminant function could be accounted for by the differences in gender (males vs. females). Both partial eta squared and the squared canonical correlation coefficient denoted a small effect (see Table 5 of Structure Matrix and Standardized Coefficients, for more detail). 
Based on the coefficients, attitudes $(F(1,114)=15.096, p=.00)$ demonstrated a slightly stronger relationship with the discriminant function followed by actions $(F(1,114)=15.020, p=.00)$; however, both predictors were statistically significant in contributing to the discriminant model. This indicates that actions and attitudes served as predictors for distinguishing between males and females. Females had slightly higher attitudes $(M=4.91, S D=.54)$ and actions $(M=2.91, S D=.49)$ in comparison to males attitudes $(M=4.48, S D=.61)$ and actions $(M=2.53, S D=.53)$ (see Table 6 of Group Means (SD) of Predictors of Gender, for more detail).

Table 5: Structure Matrix and Standardized Coefficients.

$\begin{array}{lllll}\text { Predictor } & \begin{array}{l}\text { Structure } \\ \text { Correlations }\end{array} & \text { Matrix } & \begin{array}{l}\text { Standardized } \\ \text { Discriminant Functions }\end{array} & \begin{array}{c}\text { Coefficients } \\ \text { for }\end{array}\end{array}$

\begin{tabular}{lll}
\hline Attitudes & .546 & .924 \\
\hline Actions & .538 & .921 \\
\hline
\end{tabular}

Table 6: Group Means (SD) of Predictors of Gender.

Predictor Male $(n=41) \quad$ Female $(n=75)$

\begin{tabular}{lll}
\hline Attitudes & $4.48(.61)$ & $4.91(.54)$ \\
\hline Actions & $2.53(.53)$ & $2.91(.49)$
\end{tabular}

By means of the sample proportions as prior probabilities, the discriminant function accurately predicted $70 \%$ of the gender in the data with a moderate number of cases classified correctly (34\% male and $88 \%$ female classified correctly). To account for the chance agreement in classification, the kappa coefficient was calculated as .25 , which is a moderate value. Cross validation exhibited that the percentage of cases correctly classified was very similar, 67\% (34\% male and 85\% female of crossvalidated cases correctly classified). This signified a strong level of consistency within the classification arrangement. The program $\mathrm{G}^{*}$ Power $(v .31)$ was used to calculate post hoc power, which was .97 indicating a sufficient amount of power.

Next, Wilks Lambda was not statistically significant for the main effects of the following cases: (a) age $\Lambda=.939, F(4,168)=1.353, p>.252$, partial $\eta^{2}=.031$, (b) instructional $\operatorname{rank} \Lambda=.951, F(2,84)$ $=2.159, p>.122$, partial $\eta^{2}=.049$, or $(\mathrm{c})$ college $\Lambda=.951, F(4,168)=1.067, p>.374$, partial $\eta^{2}=.025$. Partial eta squared suggested an inconsequential effect size for age (i.e., 25 to 44, 45 to 54, 55 or older), instructional rank (i.e., instructor or lecturer, tenure-track faculty), and college (i.e., Arts \& Humanities, Education \& Health, Business \& Sciences).

Consequentially, no statistically significant interaction effects were found for Wilks Lambda for the following cases:

(a) age and gender $\Lambda=.969, F(4,18)=.627, p>.631$, partial $\eta^{2}=.016$

(b) age and instructional rank $\Lambda=.911, F(4,168)=2.007, p<.096$, partial $\eta^{2}=.046$

(c) age and college $\Lambda=.919, F(8,168)=.901, p>.517$, partial $\eta^{2}=.041$

(d) gender and instructional $\operatorname{rank} \Lambda=.986, F(2,84)=.612, p>.545$, partial $\eta^{2}=.014$

(e) gender and college $\Lambda=.921, F(4,168)=1.769, p>.137$, partial $\eta^{2}=.040$

(f) instructional rank and college $\Lambda=.944, F(4,168)=1.238, p>.297$, partial $\eta^{2}=.029$ 
(g) age, gender, and instructional rank $\Lambda=.929, F(4,168)=1.582, p>.181$, partial $\eta^{2}=.036$

(h) age, instructional rank, and college $\Lambda=.971, \mathrm{~F}(4,168)=.628, p>.643$, partial $\eta^{2}=.015$

(i) gender, instructional rank, and college $\Lambda=.987, F(2,84)=.546, p>.581$, partial $\eta^{2}=.013$

(j) age, gender, instructional rank, and college $\Lambda=.979, F(2,84)=.913, p>.405$, partial $\eta^{2}=.021$

Partial eta squared suggested an inconsequential effect sizes for all possible interaction effects between age, gender, instructional rank, and college.

\section{Discussion}

Research question one examined whether a correlation existed between faculty attitudes and actions concerning online academic accommodations and inclusive teaching practices that incorporated UDL principles. Statistically significant results indicated that a correlation existed between faculty attitudes and actions surrounding distance education inclusive teaching practices. Therefore, as faculty attitudes towards inclusive teaching practices increased, their actions towards inclusive teaching practices also increased. Prior research on faculty teaching traditional face-to-face courses has found incongruences between faculty actions and attitudes surrounding accommodations and inclusive teaching practices. Although faculty reported strong positive attitudes towards inclusive teaching practices, their actions were contradictory (Lombardi et al., 2011). International research conducted by Lombardi et al. (2015) found that faculty attitudes were not congruent with their actions across serval subscales of the ITSI. Additionally, prior research conducted by Cook et al. (2009) found incongruences between faculty attitudes and actions surrounding disability related topics. While faculty expressed strong attitudes towards disability policies and protocols, their actions were not consistent in implementing policies and protocols (Cook et al., 2009). However, recent research conducted Hartsoe and Barclay (2017) found that correlations existed between faculty attitudes (i.e., Accommodations, Accessible Course Materials, Course Modifications, Inclusive Lecture Strategies, Inclusive Classroom, and Inclusive Assessment), knowledge (i.e., Campus Resources) and confidence (i.e., Disability law) (p. 229). Therefore, the findings of this study and Hartsoe and Barclay's most recent finding may suggest that attitudes surrounding inclusive teaching practices may be increasing in acceptance and adoption within academia (Hartsoe and Barclay, 2017).

Next, research question two examined if there were significant differences in faculty attitudes and actions towards inclusive teaching practices based on demographic characteristics, such as age, gender, instructional rank, and college affiliation. Statistically significant differences were found in gender with females overall mean scores higher in attitudes and actions in comparison to males overall mean scores in actions and attitudes. This finding is consistent with the prior research that females teaching face-to-face courses have tended to score higher than males towards initiating inclusive teaching practices (Baggett, 1993; Benham, 1995; Fonosch \& Schwab, 1981; Lombardi et al., 2013, Zhang, Landmark, Reber, Hsu, Kwok, \& Benz, 2010). Prior research by Baggett (1993) found a significant percentage of female faculty had positive attitudes towards students with disabilities in comparison to males. Benham (1995) also found that both gender and teaching experience were two factors that influenced faculty attitudes towards students with disabilities. Similarly, Lombardi et al. (2013) asserted a number of prior research studies (Leyser, Vogel, Wyland, \& Brulle, 1998; Lombardi et al., 2011; Lombardi \& Murray, 2011; Murray, Wren, Stevens, \& Keys, 2009; Skinner, 2007) that identified gender as a factor commonly associated with faculty attitudes concerning students with disabilities. Lombardi specifically examined mean subscale scores and identified that females with prior training on disability topics scored highest on the Accommodations, Disability Law and Concepts, Inclusive Lecture Strategies, and Inclusive Classroom subscales of the ITSI instrument (Lombardi et al., 2013, 
p. 225). Moreover, findings by Hartsoe and Barclay (2017) also upheld that females tended to possess higher levels of attitudes, knowledge, and confidence towards implementing inclusive teaching practices.

Statistically significant differences were not found surrounding faculty age and inclusive teaching practices. This finding was consistent with the prior research. Prior research examining faculty age has been mixed, but a number of studies have found no statistically significant differences between age and faculty attitudes towards inclusive teaching practices (Baggett, 1993; Benham, 1995; Dallas \& Sprong, 2015; McGee, 1989; Schoen, Uysal, \& McDonald 1986; Williamson, 2000). Research by Vogel, Leyser, Wyland, and Brulle (1999), found younger faculty were more likely than older faculty to possess positive attitudes towards initiating inclusive practices, and research by Gawronski et al. (2016) found that Caucasian faculty ages thirty-five to forty-four scored higher within inclusive teaching practices. In contrast, research conducted by Dallas and Sprong (2015) revealed that faculty age did not influence attitudes towards inclusive teaching practices.

Concerning faculty instructional rank, statistically significant results were not found between instructional rank, and attitudes and actions surrounding online inclusive teaching practices. This finding is consistent with some of the prior research that has not found statistically significant differences (Rao, 2002; Williamson 2000). However, recent research using the ITSI instrument has found statistically significant results regarding faculty rank. For instance, in recent research the findings have suggested that non-tenured (i.e., instructors or assistance professor) were more likely to incorporate inclusive teaching practices and make accommodations in comparison to tenured faculty (Dallas \& Sprong, 2015; Murray et al., 2009; Lombardi et al., 2011). Zhang et al. (2010) found that instructors tended to have stronger positive attitudes towards students with disabilities. Research by Hartsoe and Barclay also found that associate professors were significantly less likely than professors, visiting instructors, and adjunct instructors to provide students with course modifications. The research has suggested that these differences in ranks may be explained by the degree of labor and time faculty at different tenure ranks may be willing to invest (Hartsoe \& Barclay, 2017; Tunguz, 2016).

Lastly, statistically significant differences were not found between college affiliation, and attitudes and actions surrounding online inclusive teaching practices. This finding was not consistent with the prior research. Prior research has found that faculty from the college of education, liberal arts, and architecture have tended to hold stronger inclusive teaching attitudes in comparison to other concentration areas, such as engineering, business, and science professions (Rao, 2002, Rao \& Gartin, 2003; Murray et al., 2009; Schoen et al., 1986; Vogel et al., 1999; Williamson, 2000). Prior research has found that faculty from the college of arts and humanities have also tended to expresses comfort towards implementing accommodations for students with disabilities in contrast to faculty from mathematics and science colleges (Bourke, Strehorn, \& Silver, 2000; Vogel et al., 1999). Specifically, Vogel et al. (1999) identified that faculty from the college of education were more willing to make testing accommodations in comparison to other faculty.

\section{Implications for Practice}

This study provided a variety of implications for practice within postsecondary settings. First, the results of this study add to the scientific literature surrounding inclusive teaching practices and Universal Design for Learning (UDL). Dallas and Sprong (2015) asserted that the ITSI is the "only survey known to incorporate principles from the three major educational UD models (e.g., UDI, UDL, UID)" (p.20). In the past, the ITSI has only been used to examine postsecondary faculty who were teaching face-to-face lecture courses (Cook et al., 2009, Dallas \& Sprong, 2015; Lombardi et al., 2011; Lombardi et al., 2015), and to examine postsecondary student attitudes (Gawronski et al., 2016). This

is the first study to use the ITSI-DE to focuses specifically on distance education environments, and 
examine the attitudes and actions of postsecondary distance educators by adapting the ITSI. Moreover, this study was unique in examining a correlation between faculty attitudes and actions that prior studies have not explored in relation to distance education environments. Therefore, the results of this study have added to the scientific knowledge surrounding faculty attitudes and actions towards online inclusive teaching practices, and provided a foundation to build on by adapting an existing instrument to focus on distance education environments.

Next, the results of this study add to the practical knowledge of postsecondary administrators and disability service providers that work directly with faculty. For instance, the results of this study may be used to target specific populations of faculty for training, and utilized to guide the type of training method that is offered to faculty who are preparing to teach distance education courses. Rogers' diffusion of innovations theory affirmed that increasing "awareness-knowledge," "how-to knowledge," and "principles-knowledge" of an innovation is the first stage associated with adopting an innovation. Research by Huang et al. (2011) theorized that faculty awareness of technology innovations most strongly influenced the adoption of a new technology. Prior research has speculated that a variety of factors, such as technical ease, support from administration, technology preferences, motivation, and method of learning all influence faculty decisions to adopt new technology innovations (Porter \& Graham, 2016; Samarawickrema \& Stacey, 2007). Prior research has contended that faculty professional development programs need to be created to provide content that meets faculty needs and frequently offers opportunities for content review (Terosky \& Heasley, 2015). Prior research has also recommended delivering a variety of training methods and incentives to offer sufficient aid to faculty in implementing UDL principles within online courses (Gladhart, 2010; Smith, 2012). Moreover, offering faculty refresher trainings on UDL is recommended to enhance knowledge and skills throughout the years as technology changes.

Additionally, postsecondary administrators could utilize the ITSI-DE instrument informally to learn more about faculty attitudes and actions surrounding online inclusive teaching practices, guide decisions relating to outreach, training, and make fiscal budgetary decisions. Prior research has asserted attitudinal responses may be influenced by a variety of factors that may be categorized into cognitive, affective, and behavioral responses (Bunk, Li, Smidt, Bidetti, \& Malize, 2015; Kroenung \& Eckhardt, 2011). Organizationally, factors such as social approval, level of benefit, and degree of effort may all affect the adoption of new concepts or innovations (Oguz, 2016). To create a culture of change increasing faculty knowledge and consciousness of online inclusive teaching practices will require communication to be spread "top-down" to all institutional personnel (Burgstahler \& Cory, 2008). Rogers' diffusion of innovations theory upholds that communication channels within an institution are a powerful medium for the transmission of innovations (Ashley, 2009). Individuals also vary in their willingness to adopt new technology concepts or practices (Rogers, 2003); therefore, it would be beneficial for postsecondary institutions to utilize the ITSI-DE instrument to gage faculty attitudes and actions towards the adoption of online inclusive teaching practices. Enhancing the rate of adoption of online inclusive teaching strategies will require a further understanding faculty perceptions and knowledge towards UDL concepts because as Baltaci-Goktalay (2006) stated "educational change begins with what teachers do and think" (p. 1).

\section{Limitations}

As with all research studies, it is important to note the limitations associated with this research. First, the faculty were not randomly selected thus generalizations are limited to the characteristics of those who responded to the survey. The results of this study may also lack generalizability to institutions 
beyond the one sampled. Therefore, the results of this study may only be generalizable to large fouryear metropolitan research universities.

Conversely, the sample size for this study was de-limited in a variety of ways, which decreased the analytic sample size. While the sample size was robust enough to conduct all the analyses in the study, a larger sample size would be preferable towards conducting exploratory factor analysis (EFA) procedures. Prior research has recommended that a sample include, at a minimum, 100 participants to conduct an EFA (Gorsuch, 1983; Kline, 1994; Pearson \& Mundform, 2010). However, the consensus in the literature has been mixed with regard to the ideal sample size. For instance, Comrey and Lee cited in Pearson and Mundform (2010) that at least 200 participants are recommended to provide a fair sample adequacy (Comrey \& Lee, 1992). Other authors have also recommended minimum ratios of the sample size to the number of items (n:l). For example, Catell (1978) recommended using three to six participants per item, Gorsuch (1983) recommended using five participants per item, and Everitt (1975) and Nunnally (1978) suggested ten participants per item (Pearson \& Mundform, 2010). Moreover, while the exploratory factor analysis results provide some evidence of internal validity supporting the attitudinal scores obtained from the ITSI-DE, more research is needed to examine and compare the results of the adapted ITSI-DE instrument to recent exploratory factor analysis results for the ITSI instrument.

\section{Recommendations for Future Research}

Within this study, a significant correlation was found between faculty attitudes and actions, which indicated that as faculty attitudes towards inclusive teaching practices increased so did their actions towards inclusive teaching practices. One unique aspect surrounding the sample was that all faculty members had completed a distance education training course prior to teaching online, and may have been exposed to inclusive teaching practices depending on when the course was completed. However, the study cannot support causation and measure the impact that the distance education training had on faculty. Therefore, based on the results of this study future research is needed to further assess the impact that training has on distance education faculty attitudes and actions towards inclusive teaching practices by utilizing a pre and post-test experimental design.

Additionally, future research could seek to identify if differences exist in attitudes and actions surrounding inclusive teaching practices between faculty teaching primarily face-to-face and online courses, and if so examining those differences further as well as the factors that may contribute to those differences. Qualitative research specially exploring differences in attitudes and actions between faculty teaching face-to-face and online courses would be beneficial to conceptualize faculty perspectives. A qualitative study may further elucidate the underlying reasons and motivations behind faculty attitudes and actions that a quantitative study is unable to capture. Moreover, it would be beneficial to replicate this study within multiple institutions to enhance the generalizability as well as the sample size. A lack of research surrounding this topic specifically exists within the community college sector. Gawronski et al. (2016) was one of the first to conduct research within the community college sector surveying face-to-face faculty and students with the ITSI instrument. Lastly, future research should explore the differences found among gender to elucidate the factors that may influence male and female attitudes and actions towards inclusive teaching practices.

\section{Conclusions}

Prior research concerning postsecondary faculty attitudes and actions towards inclusive teaching practices has focused on examining face-to-face instructors. This is one of the first research studies to 
use the ITSI-DE to examine postsecondary faculty attitudes and actions surrounding distance education inclusive teaching practices. As distance education and student diversity continue to grow within postsecondary settings supporting faculty towards utilizing inclusive teaching practices that incorporate Universal Design for Learning (UDL) principles is vital towards increasing access and decreasing barriers for diverse student learners. Universal Design for Learning (UDL) is an effective approach to support a wide range of diverse student learners and decrease barriers for students with disabilities. The UDL approach can decrease barriers for students by increasing online accessibility and usability with adaptive technologies for students with disabilities. Therefore, it is important for faculty especially distance educators to become familiar with the incorporation of UDL concepts within online courses.

Effective faculty development programs utilizing a variety of approaches to meet faculty needs that are grounded in adult learning theory are necessary to prepare faculty to incorporate inclusive teaching strategies within distance education courses. Within the literature, there are a number barriers associated with teaching online courses. Therefore, in addition to supporting faculty knowledge and skills postsecondary institutions should also consider ways to enhance faculty motivation. It is important for postsecondary administrators to find ways to boost faculty intrinsic motivation, such as through tenure earning recognition, creating environments that value and reward inclusive teaching, and increasing faculty awareness on the positive aspects associated with incorporating UDL principles. Within organizations, administrators may influence the spread of an innovation through the degree of support they provide towards embracing an innovation.

Within postsecondary institutions, faculty members exert a tremendous influence over the educational experiences and retention of students. Therefore, it is important for postsecondary institutions to offer appropriate training as well as create a positive climate that recognizes the importance of applying inclusive teaching practices to meet technology growth demands, and offer accessibility to diverse student learners. While it is impossible to offer absolute universal design to all students, fostering greater accessibility and usability within online courses is imperative to minimize the barriers experienced by students with disabilities. In doing so postsecondary institutions will need to establish a collaborative mission across departments to create a united effort and consistency towards implementing innovative teaching methods and inclusive teaching practices. It is unrealistic to place sole responsibility on faculty or particular departments to support the accessibility needs of all students. Gladhart (2010) asserts that a realistic approach to sustaining the implementation of UDL within online programs will require the development of a strong infrastructure that provides an assortment of resources, professional support, and teaching incentives that emphasize the importance of inclusive teaching practices. Only collectively the adoption of inclusive teaching practices may be inspired, edified, and sustained within postsecondary institutions to create preeminent distance education programs that enhance student outcomes.

\section{References}

Ann Dell, C., Dell, T. F., \& Blackwell, T. L. (2015). Applying Universal Design for Learning in Online Courses: Pedagogical and Practical Considerations. The Journal of Educators Online-JEO, 13(2).

Ashley, S. R. (2009). Innovation diffusion: Implications for evaluation. In J. M. Ottoson \&P. Hawe (Eds.), Knowledge utilization, diffusion, implementation, transfer, and translation: Implications for evaluation. New Directions for Evaluation, 124, 35-45.

Bacow, L. S., Bowen, W. G., Guthrie, K. M., Lack, K. A., \& Long, M. P. (2012). Barriers to adoption of online learning systems in U.S. higher education. EDUCAUSE Review, 47(4). 
Baggett, D. W. (1993). Study of the University of Massachusetts at Amherst faculty's knowledge of disabilities, experience with educating students with disabilities, and attitudes that faculty possess towards students with disabilities. (Publication No. 9329561) [Doctoral Dissertation, University of Massachusetts.] Dissertation Abstracts International.

Baltaci-Goktalay, S. (2006). Faculty adoption of online technology in higher education. The Turkish Online Journal of Educational Technology, 5(4).

Bastedo, K., Sugar, A., Swenson, N., \& Vargas, J. (2013). Programmatic, systemic, automatic: an online course accessibility support model. Journal of Asynchronous Learning Networks, 17(3).

Benham, N. E. (1995). Faculty attitudes and knowledge regarding specific disabilities and The Americans with Disabilities Act. (Publication No. 9615256) [Doctoral Dissertation, University of Southern Mississippi]. Dissertation Abstracts International.

Black, R. D., Weinberg, L. A., \& Brodwin, M. G. (2014). Universal design for instruction and learning: A pilot study of faculty instructional methods and attitudes related to students with disabilities in higher education. Exceptionality Education International, 24(1), 48-64.

Bourke, A. B., Strehorn, K. C., \& Silver, P. (2000). Faculty members' provision of instructional accommodations to students with LD. Journal of Learning Disabilities, 33(2), 26-32.

Bunk, J., Li, R., Smidt, E., Bidetti, C., \& Malize, B. (2015). Understanding faculty attitudes about distance education: The importance of excitement and fear. Online Learning, 19(4).

Burgstahler, S. E., \& Cory, R. C. (2008). Universal design in higher education from principles to practice. Cambridge, Massachusetts: Harvard Education Press.

Burgstahler, S., Corrigan, B., \& McCarter, J. (2004). Making distance learning courses accessible to students and instructors with disabilities: A case study. Internet and Higher Education, 7, 33-246.

Center for Applied Special Technology. (2020, March). UDL on campus universal design for learning in higher education. http://udloncampus.cast.org/home

Cattell, R. (1978). The Scientific Use Of Factor Analysis. New York: Plenum.

Cercone, K. (2008). Characteristics of adult learners with implications for online learning design. Association for the Advancement of Computing in Education Journal, 16(2), 137-159.

Cohen, J. (1988). Statistical power analysis for the behavioral sciences (2nd ed.). Hillsdale, NJ: Lawrence Earlbaum Associates.

Cokluk, O., \& Kocak, D. (2015). Using Horn's Parallel analysis method in exploratory factor analysis for determining the number of factors. Educational Sciences: Theory \& Practice, 16, 537-551.

Cole, J. E., \& Kritzer, J. B. (2009). Strategies for success: Teaching an online course. Rural Special Education Quarterly, 28(4), 36-40.

Comrey, A., \& Lee, H. (1992). A first course in factor analysis. Hillsdale, NJ: Erlbaum.

Cook, L., Rumrill, P. D., \& Tankersley, M. (2009). Priorities and understanding of faculty members regarding college students with disabilities. International Journal of Teaching and Learning in Higher Education, 21, 84-96.

Cox, T. D. (2013) Adult learning orientations: The case of language teachers in Peru. International Forum of Teaching and Studies, 9(1), 3-10.

Crawford, C. B., \& Koopman, P. (1979).Inter-rater reliability of scree test and mean square ratio test of number of factors. Perceptual \& Motor Skills, 49, 223-226.

Dallas, B. K., \& Sprong, M. E. (2015). Assessing faculty attitudes toward universal design instructional techniques. Journal of Applied Rehabilitation Counseling, 46(4), 18-28.

Dallas, K. B., Sprong, M. E., \& Kluesner, B. K. (2016). Multiuniversity comparison of faculty attitudes and use of universal design instructional techniques. Rehabilitation Research, Policy, and Education, 30(2), 148-160.

Dallas, B. K., Sprong, M. E., \& Upton, T. D. (2014). Post-secondary faculty attitudes towards inclusive teaching strategies. Journal of Rehabilitation, 80(2), 12-20. 
Edmonds, C. D. (2004) Providing Access to Students With Disabilities in Online Distance Education: Legal and Technical Concerns for Higher Education. American Journal of Distance Education, 18(1), 51-62.

Everitt, B. (1975). Multivariate analysis: The need for data, and other problems. British Journal of Psychiatry, 126, 237-240.

Fonosch, G. G., \& Schwab, L. O. (1981). Attitudes of selected university faculty members toward disabled students. Journal of College Student Personnel, 22(3), 229-235.

Gawronski, M., Kuk, L., \& Lombardi. (2016). Inclusive instruction: Perceptions of community college faculty and students pertaining to Universal Design. Journal of Postsecondary Education and Disability, 29(4), 331-347.

Gladhart, M. A. (2010). Determining faculty needs for delivering accessible electronically delivered instruction in higher education, Journal of Postsecondary Education and Disability, 22(3), 185-196.

Gorsuch, R. L. (1983). Factor Analysis (2nd Ed.). Hillsdale, NJ: Erlbaum.

Hahs-Vaughn, D. L. (2017). Applied multivariate statistical concepts. New York, NY: Routledge.

Hartsoe, J. K., \& Barclay, S. R. (2017). Universal design and disability: Assessing Faculty Beliefs, Knowledge, and Confidence in Universal Design for Instruction, Journal of Postsecondary Education and Disability, 30(3), 223-236.

Hayton, J. C., Allen, D. G., Scarpello, V. (2004). Factor retention decisions in exploratory factor analysis: A tutorial on parallel analysis. Organizational Research Methods, 7, 191-205.

Heale, R., \& Twycross A. (2015). Validity and reliability in quantitative studies. Evidence-Based Nursing, 18(3), 66-67.

Higher Education Opportunity Act of 2008, Pub. L. No. 110-315, \102 \& \$103 (a) (24) (2008).

Horn, J. L. (1965). A rationale and test for the number of factors in factor analysis. Psychometrica, 30(2), 179-185.

Huang, R.T., Deggs, D. M., Jabor, M. K., \& Machtmes, K. (2011). Faculty online technology adoption: The role of management support and organizational climate. Online Journal of Distance Learning Administration, 14(2).

King, K. P., \& Cox, T. D. (2011). The professors guide to taming technology. Charlotte, NC: Information Age Publishing, INC.

Kline, P. (1994). An Easy Guide ToFactor Analysis. New York: Routledge.

Knight, J. (2000, November 15-17). Toward reflective judgement in exploratory factor analysis decisions: Determining the extraction method and number of factors to retain [Paper presentation]. Annual Meeting of the Mid-South Educational Research Association, KY, Bowling green, United States.

Kroenung, J., \& Eckhardt, A. (2011). Three classes of attitude and their implications for IS research. ICIS, 1-17.

LaRocco, D. J., \& Wilken, D. S. (2013). Universal design for learning: University faculty stages of concerns and levels of use a faculty action-research project. Current Issues in Education, 16(1), 114.

Leyser, Y., Vogel, S., Wyland, S., \& Brulle, A. (1998). Faculty attitudes and practices regarding students with disabilities: Two decades after implementation of section 504. Journal of Postsecondary Education and Disability, 13(3), 1-18.

Lombardi, A. R., \& Murray, C. (2011). Measuring university faculty attitudes toward disability: Willingness to accommodate and adopt Universal Design principles. Journal of Vocational Rehabilitation, 34, 43-56.

Lombardi, A., Murray, C., \& Dallas, B. (2013). University faculty attitudes toward disability and inclusive instruction: Comparing two institutions. Journal of Postsecondary Education and Disability, 23(3), 221-232. 
Lombardi, A. R., Murray, C., \& Gerdes, H. (2011). College faculty and inclusive instruction: selfreported attitudes and actions pertaining to Universal Design. Journal of Diversity in Higher Education, 4(4), 250-261.

Lombardi, A., Vukovic, B., \& Sala-Bars, I. (2015). International comparisons of inclusive instruction among college faculty in Spain, Canada, and the United States. Journal of Postsecondary Education and Disability, 28(4), 447-460.

McLean, J. (2005). Addressing faculty concerns about distance learning. Online Journal of Distance Learning Administration, 8(4). 1-14.

McGee, K. A. (1989). Attitudes of the University of Virginia faculty and administration toward disabled college students (Publication No. 9008192) [Doctoral dissertation, University of Virginia]. Dissertation Abstracts International.

Medlin, B.D. (2001). The factors that may influence a faculty member's decision to adopt electronic technologies in instruction (Publication No. 3095210) [Doctoral dissertation, Virginia Polytechnic Institute and State University, 2001]. ProQuest Digital Dissertations.

Motte, K. (2013). Strategies for online educators. Turkish Online Journal of Distance Education, 14(2), 258-266.

Mumford, K. R., Ferron, J. M., Hines, C.V., Hogarty, K. Y., Kromrey, J. D. (2003, April). Factor retention in exploratory factor analysis: A comparison of alternative methods [Paper presentation]. Annual Meeting of the American Educational Research Association, Chicago, IL, United States.

Murray, C., Wren, C. T., Stevens, E. B., \& Keys, C. (2009). Promoting university faculty and staff awareness of students with learning disabilities: An overview of the productive learning strategies (PLuS) project. Journal of Postsecondary Education and Disability, 22, 117-129.

Norris, M., Lecavalier, L. (2009). Evaluating the use of exploratory factor analysis in developmental disability psychological research. Journal of Autism Developmental Disorders, 40(1), 8-20.

Nunnally, J. (1978). Psychometric Theory (2nd Ed.). New York, NY: McGraw-Hill.

Oguz, F. (2016). Organizational influences in technology adoption decisions: A case study of digital libraries. College of Research \& Libraries, 77(3).

Parisot, A.H. (1995). Technology and teaching: The adoption and diffusion of technological Innovations by a community college faculty (Publication No. 9542260) [Doctoral dissertation, Montana State University]. ProQuest Digital Dissertations.

Passmore, C., Dobbie, A. E., Parchman, MD, \& Tysinger, J. (2002). Guidelines for constructing a survey. Family Medicine, 34(4), 281-286.

Pearson, R. H. \& Mundform, D. J. (2010). Recommended sample size for conducting exploratory factor analysis on dichotomous data. Journal of Modern Applied Statistical Methods, 9(2), 359-368.

Polly, D., Mims, C., Inan, F., \& Shepherd, C. E. (2010). Evidence of impact: An analysis of the influence of PT3 Projects designed to transform methods courses and field experiences. Teaching and Teacher Education, 26(4), 863-870.

Porter, W. W., \& Graham, C. R. (2016). Institutional drivers and barriers to faculty adoption of blended learning in higher education. BrITSIh Journal of Educational Technology, 47(4), 748-762.

Rao, S. M. (2002). Students with disabilities in higher education: Faculty attitudes and willingness to provide accommodations (Publication No. 3079101) [Doctoral dissertation, University of Arkansas]. Dissertations \& Theses: Full Text database.

Rao, S., \& Gartin, B. C. (2003). Attitudes of university faculty toward accommodations to students with disabilities. Journal for Vocational Special Needs Education, 25(2), 47-54.

Reindl, T. (2013). Regulating online postsecondary education: State issues and options. National Governors Association.

Rogers, E.M. (2003). Diffusion of innovations (5th ed.). New York, NY: Free Press. 
Rose, D.H., \& Meyer, A. (2002). Teaching every student in the digital age: Universal design for learning. Alexandria, VA: Association for Supervision and Curriculum Development.

Sahin, I. (2006). Detailed review of rogers' diffusion of innovations theory and educational technology-related studies based on rogers' theory. The Turkish Online Journal of Education, 5(2), 14-23.

Samarawickrema, G., \& Stacey, E. (2007). Adopting web-based learning and teaching: A case study in higher education. Distance Education, 28(3), 313-333.

Schoen, E., Uysal, M., \& McDonald, C. D. (1986). Attitudes of faculty members toward treatment of disabled students reexamined. College Student Journal, 21(2), 190-193.

Seale, J. K. (2014). E-learning and disability in higher education (2nd ed.). New York, NY: Routledge.

Skinner, M. E. (2007). Faculty willingness to provide accommodations and course alternatives to postsecondary students with learning disabilities. International Journal of Special Education, 22(2), $32-45$.

Smith, K. (2012). Lessons learnt from literature on the diffusion of innovative learning and teaching practices in higher education. Innovations in Education and Teaching International, 49(2), 173-182.

Surry, D. W., Stefurak, J. T., \& Gray, R. M. (2011). Technology integration in higher education social and organizational aspects. Hershey, PA: Information Science Reference.

Tandy, C., \& Meacham, M. (2009). Removing the barriers for students with disabilities: Accessible online and web-enhanced courses. Journal of Teaching in Social Work, 29(3), 313-328.

Terosky, A. L., \& Heasley, C. (2015). Supporting online faculty through a sense of community and collegiality. Online Learning, 19(3), 147 -161.

Tunguz, S. (2016). In the eye of the beholder: emotional labor in academia varies with tenure and gender. Studies in Higher Education, 41(1), 3-20.

National Center for Education Statistics, Integrated Postsecondary Education Data System. (2018). Fall Enrollment component. U.S. Department of Education. https://nces.ed.gov/fastfacts/display.asp?id $=80$.

National Center for Education Statistics (2019). Digest of Education Statistics, 2017, Chapter 3. U.S Department of Education https://nces.ed.gov/fastfacts/display.asp?id=60.

Vogel, S. A., Leyser, Y., Wyland, S., \& Brulle, A. (1999). Students with learning disabilities in higher education: Faculty attitude and practices. Learning Disabilities Research \& Practice, 14(3), 173-187.

West, E. A., Novak, D., \& Mueller, C. (2016). Inclusive instructional practices used and their perceived importance by instructors. Journal of Postsecondary Education and Disability, 29(4), 363374.

Weston, T. J. (2005). Why faculty did- and did not- integrate instructional software in their undergraduate classrooms. Innovative Higher Education, 30(2), 99-115.

WICHE Cooperative for Educational Technologies. (2013). Managing online education 2013: Practices in ensuring quality. Western Interstate Commission for Higher Education. https://wcet.wiche.edu/initiatives/research/managing-online-education-survey

Williamson, P. T. (2000). Attitudes of the Troy State University Dothan faculty toward students with disabilities (Publication No. 9965743) [Doctoral dissertation, Auburn University]. WorldCat.

Zhang, D., Landmark, L., Reber, A., Hsu, H., Kwok, O., \& Benz, M. (2010) University faculty knowledge, attitudes, and practices in providing reasonable accommodations to students with disabilities. Remedial and Special Education, 31(4), 276-286. 